Original article (short paper)

\title{
Effects of exercise training with blood flow restriction on blood pressure in medicated hypertensive patients
}

\author{
Marcos Antônio Cezar \\ Universidade do Oeste de Santa Catarina, Chapecó, SC, Brasil \\ Clodoaldo Antônio De Sá \\ Vanessa da Silva Corralo \\ Sedinei Lopes Copatti \\ Guilherme Augusto Gonzaga dos Santos \\ Universidade Comunitária da Região de Chapecó, Chapecó, SC, Brasil \\ Marzo Edir da Silva Grigoletto \\ Universidade Federal de Sergipe, Aracajú, SE, Brasil
}

\begin{abstract}
The development of non-pharmacological approaches to hypertension (HA) is critical for both prevention and treatment. This study examined the hemodynamic and biochemical responses of medicated hypertensive women to resistance exercise with blood flow restriction (vascular occlusion). Twenty-three women were randomly assigned to one of three groups: High intensity strength training $(\mathrm{n}=8)$; low-intensity resistance exercise with occlusion $(\mathrm{n}=$ 8 ); and control $(\mathrm{n}=7)$. The first two groups underwent eight weeks of training performed twice a week, including three series of wrist flexion exercises with or without vascular occlusion. The exercised with occlusion group showed pre- to post-test reduction in systolic and diastolic blood pressure, mean arterial pressure, and double product, whereas the other groups showed no significant hemodynamic changes. In conclusion, resistance exercise during 8 weeks was effective in lowering blood pressure in medicated hypertensive subjects.
\end{abstract}

Keywords: hypertension, exercise therapy, resistance training

\section{Introdução}

The prevalence high blood pressure in adults is nearly $30 \%$ all over the world, a condition responsible for half of all deaths from stroke and vascular injury (World Health Organization, 2013). It is estimated that $22.7 \%$ of adults in Brazil are hypertensive with higher prevalence in women (25.4\%) than in men (19.5\%) (Brasil, 2012). Various strategies for prevention or treatment of hypertension (HA) have been implemented among them physical exercise practice is well recognized an important approach in cardiovascular health promotion. Indeed, exercise plays a key role not only in the prevention and treatment of hypertension (Paffenbarger, Kampert \& Lee, 1997; Paffenbarger, 2000), but also in improvement of overall life quality for patients and reduction in the use of pharmacological drugs (Pescatello et al., 2004; Rolim, Amaral \& Monteiro, 2007; Nelson et al., 2007; Vitor, Sakai \& Consoni, 2009). Although aerobic exercise is recommended for hypertensive individuals (Sanhueza \& Mascayano, 2006; Westhof et al., 2007), some studies, particularly from the 1990's, also demonstrate positive results of resistance exercise (Fleck, 1988; Martel et al., 1999; Byrne \& Wilmore, 2000; Hagerman, et al., 2000; Terra et al., 2008; Costa, Gerage, Gonçalves, Pina $\&$ Polito, 2010). However, reduction and maintenance of blood pressure (BP) are typically demonstrated only at high exercise intensities (e.g., 70 and 90\% of maximum repetition) and employ strength-training routines involving several muscle groups at each session, at a frequency of three times a week (Brand, et al. 2013; Cardoso et al., 2010; Terra et al., 2008). These training routines require an onerous and often unfeasible structure, and intervention programs for large population groups. Moreover, the exercise intensities used in these programs are not always well tolerated by subjects with hypertension, mainly due to obesity and musculoskeletal limitations common in this population.

Continued pursuit of low risk, exercise-based protocols with positive results for hypertension treatment is essential, as such information may subsidize current intervention programs that have demonstrated success in reducing high blood pressure and associated health risks. Low intensity exercise with blood flow restriction (BFR) may be an effective additional tool in the treatment of hypertension. This technique can yield similar results to those achieved with very intense training, including strength and endurance-type training (Renzi, Tanaka, \& Sugawara, 2010; Wernbom, Augustsson \& Thomeé, 2006; Laurentino et al., 2008; Reeves et al., 2006; Takarada, Sato \& Ishi, 2002).

Several studies have shown that exercise training with BFR, also called 'occlusion training' (OT), results in marked 
recruitment of motor units (Moore et al., 2004), increased concentrations of growth hormone $(\mathrm{GH})$, insulin, and norepinephrine (Takarada et al., 2002; Iida et al., 2005; Abe, Beekley, Hinata, Koizumi \& Sato, 2005), reduction in myostatin expression (Drummond, Fujita, Abe, Dreyer, Volpi \& Rasmussen, 2008; Laurentino, 2010), and increased expression of insulin-like growth factor (IGF-1) (Takano et al., 2005), among other changes. Studies have shown that even low intensity exercise with blood flow restriction produces light muscle damage, increasing inflammatory markers such as interleukin-6 (IL-6) (Umbel et al., 2009). IL-6 has been associated with increased plasma cortisol (CORT) levels (Steensberg, Fischer, Keller, Moller \& Pederson, 2003), which effects on metabolism is well described. Together, these responses create a physiological condition that promotes chronic positive effects upon blood pressure providing significant health benefits for hypertensive patients.

To our knowledge, few studies have investigated the acute effects (Satoh, 2011; Sakamaki, Fujita, Sato, Bemben \& Abe, 2008), and none have investigated the chronic effects of resistance exercise in hypertensive individuals with vascular occlusion. Studies of exercise with BFR in hypertensive individuals are inexpensive and procedurally simple (i.e., wrist flexion exercises with BFR), and may be used as an effective intervention strategy treatment for hypertension. Based on these considerations, this study examined the hemodynamic and biochemical responses to resistance exercise with vascular occlusion in hypertensive women.

\section{Methods}

\section{Ethical compliance}

The objectives, procedures, and potential risks and benefits associated with this research were verbally explained in full detail to subjects, and all participants signed a consent form in duplicate, in accordance with the rules of Resolution No. 466/2012 of the National Health Council. This study was approved by the Ethics Committee for Human Research at the Universidade Comunitária da Região de Chapecó (Protocol No 118/13).

\section{Subjects}

The study sample consisted of volunteers with clinical diagnosis of hypertension and under medical treatment registered in Efapi District Basic Health Unit in the city of Chapecó, Santa Catarina, Brazil. Volunteers did not participate in any exercise programs in the six months leading up to this study. Women with SBP and DBP greater than 160 and $105 \mathrm{mmHg}$, respectively, body mass index (BMI) greater than $35 \mathrm{~kg} / \mathrm{m}^{2}$, or morphological and functional limitations that prevented the proposed exercise program were excluded. Of the 36 volunteers eligible for the study, nine were excluded based on these criteria (i.e. initial $\mathrm{N}=27$ ). All subjects underwent anti-hypertensive therapy which was maintained throughout the study. Subjects visited the clinic every two weeks for blood pressure monitoring and dietary guidance.

\section{Randomization}

An independent researcher with no involvement in data collection or analyses performed the randomization process. The 27 subjects were randomly assigned to one of the following groups: low intensity wrist flexion exercise training with blood flow restriction (WFBFR, $\mathrm{n}=10$ ), low intensity wrist flexion exercise training alone (WFE, $n=10$ ) and the control group, with no structured physical exercise program $(\mathrm{CG}, \mathrm{n}=$ 7). Over the study period, the control group visited the clinic every two weeks for hypertension monitoring and received the same recommendations as the WFBFR and WFE groups, including instructions to maintain typical daily activities. The control group was also monitored throughout the study (during visits) to confirm that they are not participating in an exercise program. The sample design was balanced for age, maximum dynamic force, and BMI.

Over the course of the study, one woman in the WFBFR group dropped out for personal reasons. One individual in the WFBFR and two individuals in the WFE were also later excluded for not meeting attendance criteria (i.e., missing two consecutive sessions or three or more sessions over eight weeks of treatment). Thus, the final analysis included 23 subjects (Figure 1): Eight in the WFBFR group (age: $63.75 \pm 11.58$ years; BMI: $27.28 \pm 4.52 \mathrm{~kg} / \mathrm{m}^{2}$ ), eight in the WFE group (age: 59.0 \pm 13.03 years; BMI: $30.06 \pm 4.91 \mathrm{~kg} / \mathrm{m}^{2}$ ), and seven in the $\mathrm{CG}$ (age: $57.3 \pm 8.17$ years; BMI: $28.8 \pm 3.65 \mathrm{~kg} / \mathrm{m}^{2}$ ).

\section{Data collection}

All data were collected 48 hours before initiation of the exercise program, and 48 hours after the end of the last training session.

\section{Heart rate and blood pressure assessment}

Blood pressure (BP) and heart rate (HR) measurements were taken after a fasting period of 10 to 12 hours, with a 15-minute acclimation period in a temperature controlled room. Both pre- and post-test measurements were taken on the same day of blood collection. BP and HR were measured before each training session after the subjects remained at rest for 10 to 12 minutes. Blood pressure was measured using a mercury sphygmomanometer (Erkamater TM E300, Germany) and a stethoscope (Brand Premium $^{\mathrm{TM}}$ ). The remaining BP measurement procedures were performed in accordance with standards from the VI Brazilian Guidelines for Arterial Hypertension (Sociedade Brasileira de Cardiologia, Sociedade Brasileira de Hipertensão and Sociedade Brasileira de Nefrologia, 2010). Heart rate was evaluated using a heart rate sensor (Polar ${ }^{\mathrm{TM}} \mathrm{RS}-800$, Finland). We also estimated the double product (DP) and mean arterial pressure (MAP). The DP was calculated by multiplying the SBP and HR; to MAP estimate we used the following equation:

$$
\mathrm{MAP}=\mathrm{DBP}+(\mathrm{SBP}-(\mathrm{DBP} \times 0.333)) .
$$




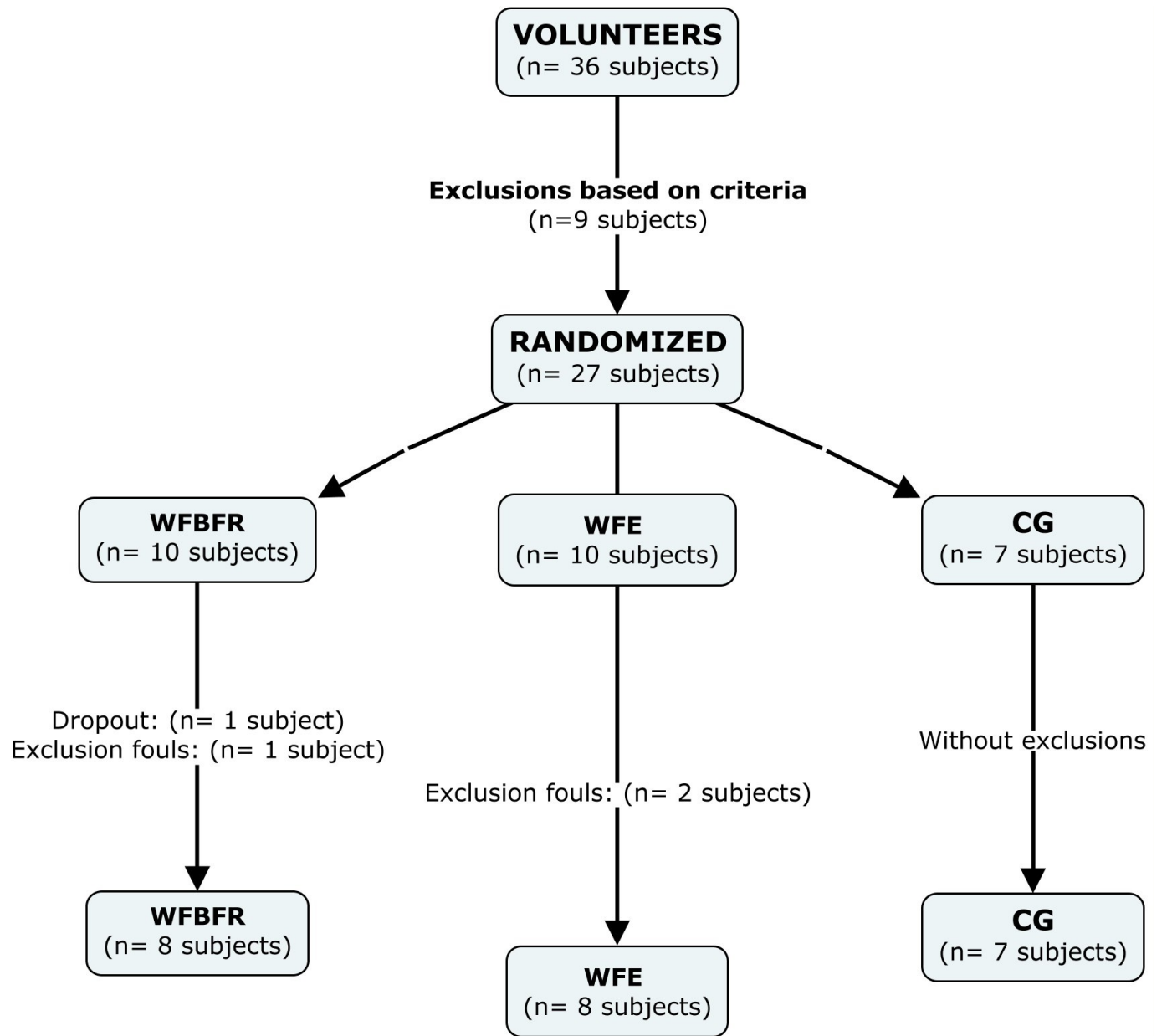

Figure 1. Organization Chart of the study.

\section{Collection and analysis of blood samples}

Blood samples were collected by an approved pharmacist in the Exercise Physiology and Biochemistry laboratory at the Universidade Comunitária da Região de Chapecó (Unochapecó). For analysis of plasma CORT and IL-6 concentrations, five ml of blood was collected from subjects via antecubital vein puncture using a vacuum system (vacuteiner) and sterile tubes with separator gel. Immediately after blood collection, samples were centrifuged at 2,500 rpm for 10 minutes. Serum was separated into two aliquots of at least one milliliter each then frozen at -20 ${ }^{\circ} \mathrm{C}$. One aliquot was sent to the Brazil Diagnostics Laboratory (São José dos Pinhais, PR) for further analyses.

IL-6 concentrations were determined by sequential enzymatic chemiluminescent immunoassay using an automated clinical chemistry analyzer (Immulite $1000^{\mathrm{TM}}$, SIEMENS, Sweden). We performed radioimmunoassay using a radioactive counter (COBRAAuto Gamma Counter II ${ }^{\mathrm{TM}}$, Canberra Packard Company, Australia) to determine cortisol concentrations.

In the two weeks leading up to the study, two familiarization sessions were held in which the volunteers experienced all the study procedures. In the first session, subjects were shown the wrist flexion exercise with and without vascular occlusion. The second session included one-repetition maximum (1-RM) tests for evaluation of maximum dynamic strength to determine the training load of each group. In subsequent weeks, subjects arrived at the laboratory for blood collection between 7:30 and 8:00 am, after a fasting period of 10 to 12 hours without the use of any medications. Upon arrival at the laboratory, each volunteer was allowed to rest for a period of 15 minutes. HR was monitored for five minutes (after a minimum of 10 minutes absolute rest) and resting HR was considered the lowest value obtained in this period. BP measurements and blood sample collections were then carried out as described above.

Subjects were instructed on the necessary pre- and post-test precautions collectively in the first meeting, and individually in a second meeting. All procedures performed in the pre-test were repeated after the eight-week training period.

\section{Training regimen}

Both groups underwent eight weeks of resistance training with two exercise sessions per week, performed on Tuesdays and Thursdays. Two previously trained researchers monitored each subject throughout the exercise sessions. Before each session all subjects (WFBFR and WFE) were kept at rest for five minutes, after which blood pressure was measured. From the 
measurement of blood pressure at rest, occlusion pressure was calculated for use during exercise in the WFBFR group $(70 \%$ of SBP). Subjects were individually monitored during sessions, and all relevant information from sessions was recorded on a control card for further analysis.

The WFBFR group performed wrist flexion exercise with vascular occlusion implemented on the medial portion of both arms using sphygmomanometers (Erkamater ${ }^{\mathrm{TM}}$ E300, Germany). Sphygmomanometer pressure was equivalent to $70 \%$ of the subject's resting systolic pressure (maintained from the beginning of the exercise period until the end of the last series). All participants remained seated in a chair during exercise with torso bent slightly forward and supinated forearms supported by an upholstered wood base resting on the thighs. So that the full range of bending motion and wrist extension was possible. Each subject performed three sets with loads corresponding to $30 \%$ of their 1-RM strength at intervals of 30-seconds between sets. Exercise speed was 1.5 seconds for the concentric phase and 1.5 seconds for the eccentric phase, totaling three seconds for the full implementation of the movement. Repetition counting, exercise speed, and interval lengths between sets were controlled for using a digital metronome (Sannyt ${ }^{\mathrm{TM}}$, Personal Counter, Brazil). The 'WFE' group followed the same wrist flexion exercise protocol as the WFBFR group, except that the load used was $80 \%$ of subject 1-RM strength and without vascular occlusion. These subjects also exercised with sphygmomanometers affixed to their arms. Form and technique for exercises were standardized and continuously monitored to ensure uniformity of training protocols.

\section{Data analysis}

Traditional statistical methods were used to calculate mean and standard error of the mean. The normality of the sample was calculated using a Shapiro-Wilk test. The effect of different training regimens (WFBFR, WFE and CG, independent variables) on HR, SBP, DBP, CORT and IL-6 (dependent variables) were analyzed by ANCOVA (3 $\mathrm{x} 2$ design, with 'group' and 'time'), and the BMI was used as control covariate. A Sidak correction was used to adjust the $\mathrm{p}$ value for the number of contrasts performed. A $p$ value of $\leq 0.05$ was used the threshold for statistical significance. The percentage differences and the significance are shown in bar charts. All procedures were carried out using SPSS ${ }^{\mathrm{TM}}$ version 20.0 for Windows.

\section{Results}

Our results indicate that eight weeks of wrist flexion exercise with blood flow restriction were efficient to produce a statistically significant reduction $(p<0.05)$ in SBP, DBP, MAP and DP from pre- to post-test (Table 1). Strength exercise with vascular occlusion did not, however, produce significant changes in CORT or IL-6 concentrations. Strength training alone and control groups showed no statistically significant differences from pre- to post-test for any of the hemodynamic or biochemical parameters evaluated.

Table 1. Effects of resistance exercise (low intensity wrist flexion exercise) on cardiovascular parameters and plasma biomarkers in subjects with blood flow restriction (WFBFR), without flow restriction (WFE) and control group (CG).

\begin{tabular}{|c|c|c|c|c|c|c|}
\hline & \multicolumn{2}{|c|}{ WFBFR } & \multicolumn{2}{|c|}{ WFE } & \multicolumn{2}{|c|}{ CG } \\
\hline & Pre-test & Post-test & Pre-test & Post-test & Pre-test & Post-test \\
\hline \multirow{2}{*}{$\mathrm{SBP}(\mathrm{mmHg})$} & 145.75 & $129.75 *$ & 142.5 & 139 & 131.43 & 134.86 \\
\hline & \pm 2.84 & \pm 2.25 & \pm 3.46 & \pm 4.33 & \pm 4.44 & \pm 5.43 \\
\hline \multirow{2}{*}{ DBP (mmHg) } & 92.75 & $81.5^{*}$ & 89.25 & 90.25 & 85.14 & 85.14 \\
\hline & \pm 2.17 & \pm 2.97 & \pm 3.27 & \pm 2.66 & \pm 3.29 & \pm 3.78 \\
\hline \multirow{2}{*}{ MAP (mmHg) } & 110.41 & $97.58 *$ & 107.00 & 106.50 & 100.57 & 101.71 \\
\hline & \pm 2.16 & \pm 1.94 & \pm 1.92 & \pm 2.41 & \pm 3.40 & \pm 4.08 \\
\hline \multirow{2}{*}{ HR (bpm) } & 81.5 & 81.75 & 75.00 & 77.5 & 71.43 & 74.00 \\
\hline & \pm 4.93 & \pm 3.28 & \pm 3.78 & \pm 3.20 & \pm 4.06 & \pm 1.69 \\
\hline \multirow{2}{*}{ DP } & 11903.75 & $10617.50 *$ & 10689.50 & 10821.00 & 9458.57 & 9977.71 \\
\hline & \pm 807.87 & \pm 485.55 & \pm 618.19 & \pm 681.13 & \pm 784.22 & \pm 458.64 \\
\hline \multirow{2}{*}{$\operatorname{CORT}(\mu \mathrm{g} / \mathrm{dL})$} & 10.87 & 9.98 & 7.66 & 8.96 & 11.18 & 12.17 \\
\hline & \pm 1.26 & \pm 1.79 & \pm 1.11 & \pm 1.29 & \pm 0.94 & \pm 1.29 \\
\hline \multirow{2}{*}{ IL-6 (pg/mL) } & 2.93 & 2.78 & 2.44 & 2.34 & 2.61 & 2.56 \\
\hline & \pm 0.52 & \pm 0.26 & \pm 0.16 & \pm 0.14 & \pm 0.44 & \pm 0.26 \\
\hline
\end{tabular}

Mean and standard error of the mean for the hemodynamic variables: systolic blood pressure (SBP), diastolic blood pressure (DBP), mean arterial pressure (MAP), heart rate (HR) and double product (DP), and biochemical variables: Cortisol (CORT) and Interleukin-6 (IL-6). Statistically significant difference from pre to post-test $(p<0.05)$.

Post-test SBP, DBP and MAP in the WFBFR group significantly differed from the WFE and CG groups $(p<0.05$; see multiple comparison results in Figure 2). There were no statistically significant differences in hemodynamic variables between the GF and CG groups. The post-test double product (DP) in the WFBFR group was significantly different $(p<0.05)$ from post-test DP in the WFE and CG groups (Figure 3).

CORT e IL-6 concentrations did not differ significantly ( $p$ $>0.05$ ) from pre- to post- test in any treatment groups (Figure 4). 


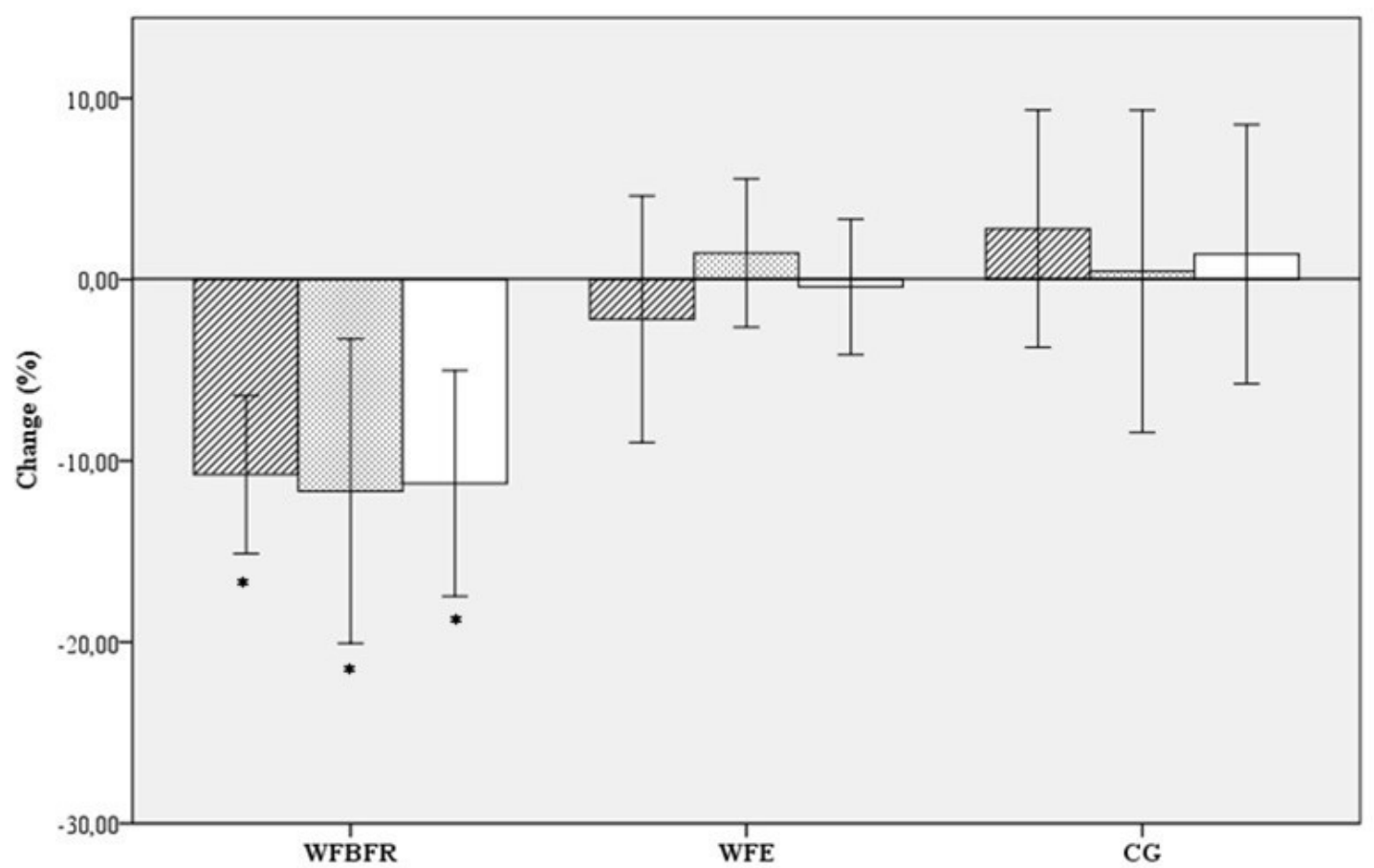

Figure 2. Percentage changes from pre- to post-test for variables: systolic blood pressure (SBP, hatched bars), diastolic blood pressure (DBP, stippled bars) and mean arterial pressure (MAP, open bars), for low intensity wrist flexion exercise with blood flow restriction (SBP), low intensity wrist flexion exercise (WFE) and control group (CG). Values are means \pm SE. * Statistically significant difference from WFE and CG to WFBFR $(p<0.05)$.

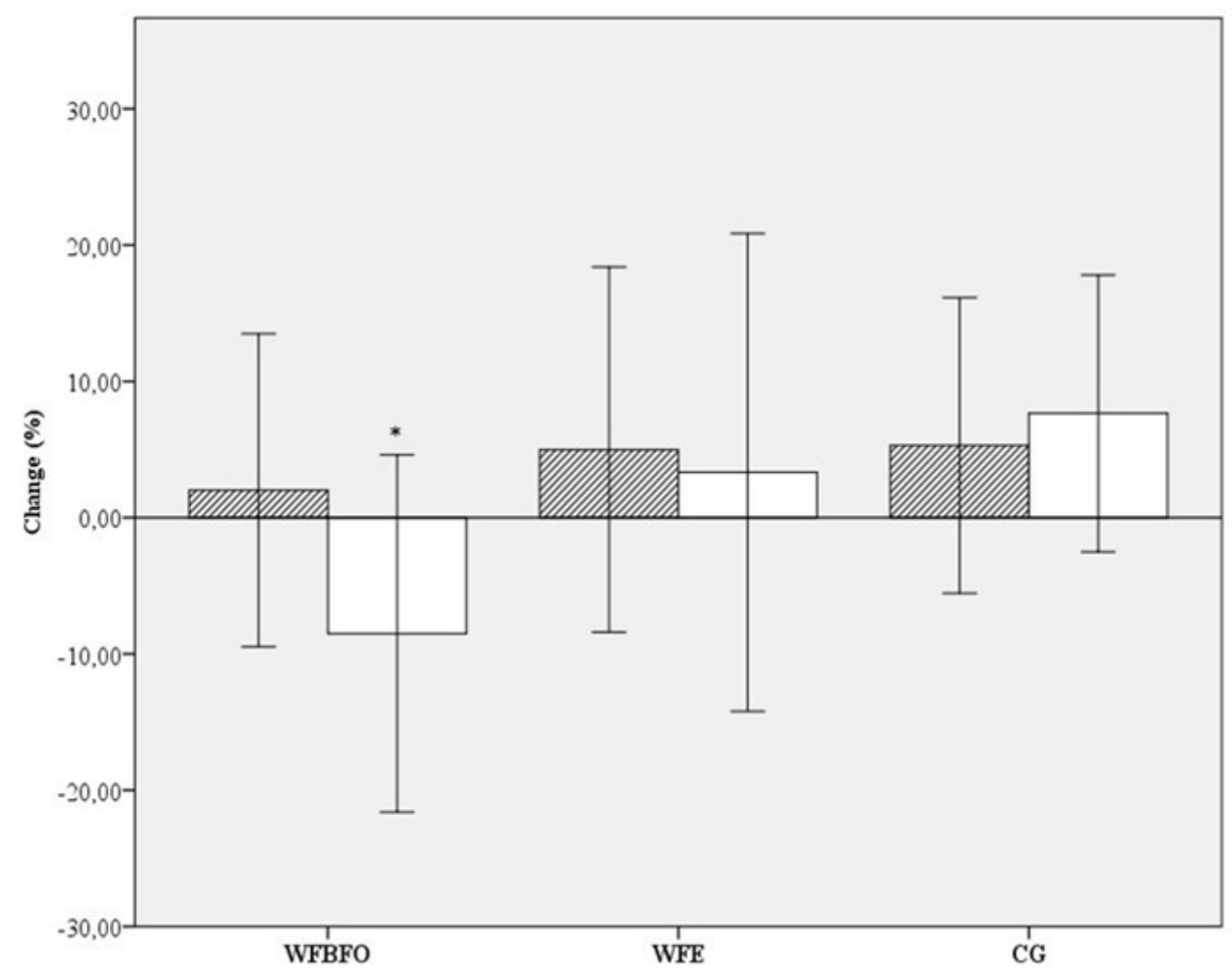

Figure 3. Percentage changes from pre to post-test for variables: heart rate (HR, hatched bars) and double product (DP, open bars), expressed as percentage changes from pre- to post-test. Values are means \pm SE. * Statistically significant difference from WFBFR to WFE and CG $(p<0.05)$. 


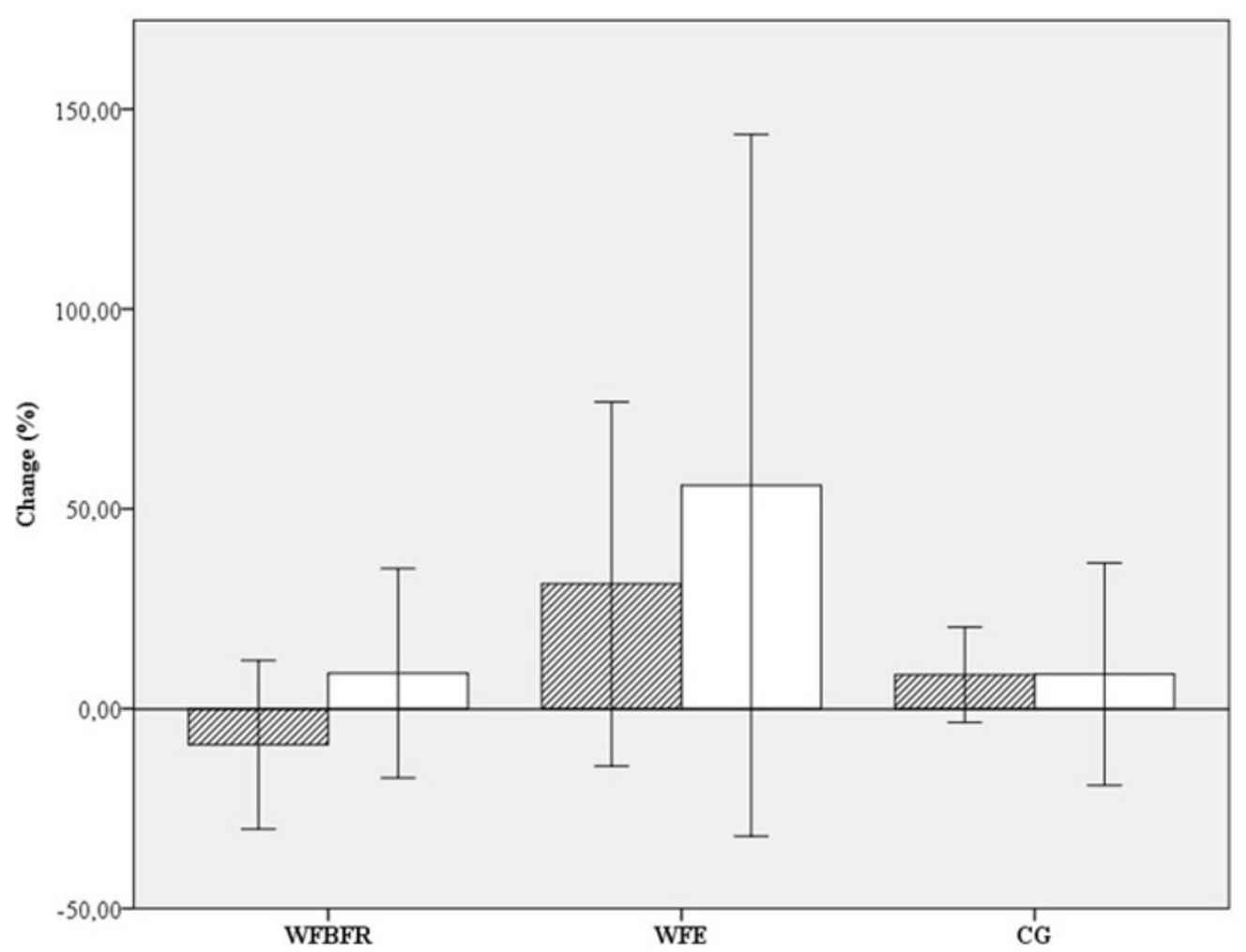

Figure 4. Effects of treatments on the variables: cortisol (CORT, hatched bars) and interleukin-6 (IL-6, open bars), expressed as percentage changes from pre- to post-test. Values are means $\pm \mathrm{SE}$.

\section{Discussion}

The main finding of this study was that eight weeks of wrist flexion exercise training with $30 \%$ of maximum dynamic force with vascular occlusion ( $70 \%$ of the resting SBP) was sufficient to reduce SBP, DBP, MAP and DP by 10.98, 12.13, 11.62 and $10.81 \%$, respectively.

Analyzing a population similar to this study, Araújo et al. (2014), reported a hypotensive effect of leg extension exercises with vascular occlusion in hypertensive women 60 minutes after exercise. We note that in this study, the authors used only two training sessions. Brand et al. (2013) also evaluated effects of occlusion without strength training on blood pressure and found similar results. They compared hemodynamic responses after a 48 -week strength training program without occlusion, involving hypertensive and normotensive subjects and randomly alternating sessions with loads between 40 and $70 \%$ of the 1-RM. The authors demonstrated that training was effective in reducing SBP and DBP by 4 and 6\%, respectively. It should be emphasize that these authors used not only strength exercise (with occlusion) as in our study, but a strength-training program (Brand et al. 2013). In addition, a recent study used much higher training loads and for six sessions, also yielding more pronounced changes than those reported previously (Araújo et al. 2014).

In another study, Terra et al. (2008) investigated exercise effects upon older, sedentary women undergoing treatment with anti-hypertensive medication. They employed resistance training for 12 weeks with a weekly frequency of three times. Subjects performed three sets of 12,10 and 8 repetitions per session, with loads between 60 and $80 \%$ and a significant reduction in SBP, MAP and DP at rest was found. Further, the authors reported that there were no adverse effects during training sessions, demonstrating the safety of this type of training for hypertensive populations. In agreement, Peters, Alessio and Hagerman (2006) demonstrated reduction in SBP, but not DBP, after six weeks of training using isometric handgrip exercises with a force corresponding to $50 \%$ of maximal voluntary contraction. They postulated that the mechanism involved in reduction of SBP by isometric training may be associated with changes in autonomic nervous system activity, as previously described by Taylor-Tolbert et al. (2000). These authors reported increased vagal activity mediated by hypoxia-induced oxidative stress, a characteristic of isometric exercise. Exercise with vascular occlusion has similar characteristics, thus we can infer that a mechanism mediated by hypoxia may partly explain the chronic results shown in the current study. Indeed, Pinto and Polito (2015) demonstrated that low-intensity exercise with BFR promotes hemodynamic and cardiovascular responses higher than traditional high-intensity exercise. The authors hypothesized that this response may be associated with potential capacity of BFR in enhancing systemic vascular response and the heart after load. Spranger, Krishnan, Levy, O'Leary \& Smith (2015) corroborated this hypothesis, demonstrating that the exercise 
pressor reflex (EPR) is probably involved during exercise with BFR, primarily mediated by metabolites accumulation. These acute responses may partly explain the hemodynamic responses to exercise training found in this study. Although the physiological mechanisms are not clear, our results suggest that resistance exercise with vascular occlusion and and low loads have a stronger potential to promote hypotensive effects than does moderate or high intensity exercise.

Another important finding is that training protocols did not produce major changes in CORT and IL-6 levels (Figure 4). In the WFBFR group, both CORT as the IL-6 decreased after the training period in most of the subjects. An important factor associated with cardiovascular disease is vascular inflammation, and cytokines, like IL-6, are biomarkers commonly associated with both inflammatory processes (Gomes, Macedo \& Bispo, 2009). In addition, this interleukin is associated with immune activity and IL-6 is an important inflammatory marker associated with the development of metabolic syndrome (Rexrode, Pradhan, Meek, Buring and Ridker, 2003). Furthermore, IL-6 is the first cytokine secreted into the bloodstream after exercise, reaching up to 100 times greater than the baseline. Peak concentrations occur soon after stopping exercise and gradually decrease after hours of thermal activity (Petersen and Pedersen, 2005). IL-6 release during exercise depends on exercise intensity and recovery time between training sessions (Prestes et al., 2009). All subjects in the current study had 'normal' cortisol concentrations both pre- and post-training. The fact that the CORT and IL- 6 values did not increase from pre- to post-test is also an indication that WFBFR did not represent a stress factor, and did not constitute an exercise overload for the subjects.

In conclusion, eight weeks of strength training with vascular occlusion using wrist flexion exercise performed twice a week decreased hemodynamic parameters. Conventional strength training had no significant effects on these parameters. Future studies with male subjects may enhance our understanding of the hypotensive effects of resistance exercise, and studies investigating the mechanisms leading to such responses should be emphasized. The exercise regimen used in this study was evaluated by participants, and described as easy to perform. This, coupled with training protocol efficiency, ease of implementation, low equipment costs, and modest amount of time required for exercise sessions suggest that this protocol may be introduced by physical education professionals to routines for both prevention and treatment of hypertension.

\section{References}

Abe, T., Beekley, M.D., Hinata, S., Koizumi, K., Sato, Y. (2005). Dayto-day change in muscle strength and MRI-measured skeletal muscle size during 7 days KAATSU resistance training: A case study. International Journal of Kaatsu Training Research, 1(2), 71-76.

Araújo, J.P., Silva, E. D., Silva, J.C.G., Souza, T.S.P., Lima, E.O., Guerra, I., Sousa, M.S.C. (2014). The Acute Effect of Resistance Exercise with Blood Flow Restriction with Hemodynamic Variables on Hypertensive Subjects. Journal of Human Kinetics, 29(43), 79-85.
Brand, C., Griebeler, L.C., Roth, M.A., Mello, F.F., Barros, T.V.P.B., Neu. L.D. (2013). Efeito do treinamento resistido em parâmetros cardiovasculares de adultos normotensos e hipertensos. Revista Brasileira de Cardiologia, 26(6), 435-41

Brasil. (2012). Secretaria de Vigilância em Saúde, Ministério da Saúde. VIGITEL 2011: vigilância de fatores de risco e proteção para doenças crônicas por inquérito telefônico. Brasília (DF): Ministério da Saúde, 2012.

Byrne, H.K., Wilmore, J.H. (2000). The effects of resistance training on resting blood pressure in women. Journal of Strength and Conditioning Research, 14(14), 411-8.

Cardoso, C.G., Jr., Gomides, R.S., Queiroz, A.C., Pinto, L.G., da Silveira Lobo, F., Tinucci, T., Mion Jr, D., de Moraes Forjaz, C.L. (2010). Acute and chronic effects of aerobic and resistance exercise on ambulatory blood pressure. Clinics, 65(3), 317-25.

Costa, J.B.Y., Gerage, A.M., Gonçalves, C.G.S., Pina, F.L.C., Polito, M.D. (2010). Influência do estado de treinamento sobre o comportamento da pressão arterial após uma sessão de exercícios com pesos em idosas hipertensas. Revista Brasileira de Medicina do Esporte, 16(2), 103-6.

Drummond, M.J., Fujita, S., Abe, T., Dreyer, H.C., Volpi, E., Rasmussen, B.B. Human muscle gene expression following resistance exercise and blood flow restriction. (2008). Medicine and Science in Sports \& Exercise, 40(1), 691-8.

Fleck, S.J. (1988). Cardiovascular adaptations to resistance training. Medicine and Science in Sports and Exercise, 20(1), 146-51.

Gomes, M.A., Macedo, N.C., Bispo, I.G.A. (2009). Interleucina-6, moléculas de adesão intercelular-1 e microalbuminúria na avaliação da lesão endotelial: revisão de literatura. Revista da SOCERJ, 22(1), 398-403.

Hagerman, F.C., Walsh, S.J., Staron, R.S., Hikida, R.S., Gilders, R.M., Murray, T.F., Toma, K., Ragg, K.E. (2000). Effects of high-intensity resistance training on untrained older men. I. Strength, cardiovascular, and metabolic responses. The journals of gerontology. Series A, Biological sciences and medical sciences, 55(1), 336-46.

Iida, H., Takano, H., Meguro, K., Asada, K., Oonuma, H., Morita, T., Kurano, M., Sakagami, F., Uno, K., Hirose, K., Nagata, T., Takenaka, K., Suzuki, J., Y. Hirata, Y., Furuichi, T., Eto, F., Nagai, R.,Sato, Y., Nakajima, T. (2005). Hemodynamic and autonomic nervous responses to the restriction of femoral blood flow by KAATSU. International Journal of Kaatsu Training Research, 1(2), 57-64.

Laurentino, G.C. (2010) Treinamento de força com oclusão vascular: adaptações neuromusculares e moleculares. $78 \mathrm{f}$. Tese (Doutorado) - Escola de Educação Física e Esporte, Universidade de São Paulo, São Paulo, 2010.

Laurentino, G., Ugrinowitsch, C., Aihara, A.Y., Fernandes, A.R., Parcell, A.C., Ricard, M., Tricoli, V. (2008). Effects of strength training and vascular occlusion. International Journal of Sports Medicine, 29(8), 664-7.

Martel, G.F. Hurlbut, D.E., Lott, M.E., Lemmer, J.T., Ivey, F.M., Roth, S.M., Rogers, M.A., Fleg, J.L., Hurley, B.F. (1999). Strength training normalizes resting blood pressure in 65- to 73 year-old men and women with high normal blood pressure. Journal of the American Geriatrics Society, 47(2), 1215-21.

Martel, G.F., Hurlbut, D.E., Lott, M.E., Lemmer, J.T., Ive,y F.M., Roth, S.M., Rogers, M.A., Fleg, J.L., Hurley, B.F. (1999). Strength 
training normalizes resting blood pressure in 65- to 73 year-old men and women with high normal blood pressure. Journal of the American Geriatrics Society, 47(10), 1215-21.

Moore, D.R., Burgomaster, K.A., Schofield, L.M., Gibala, M.J., Sale, D.G., Phillips, S.M. (2004). Neuromuscular adaptation in human muscle following low intensity resistance training with vascular occlusion. European Journal of Applied Physiology, 92(4-5), 399-406.

Nelson, M.F., Rejeski, J., Blair, S.N., Duncan, P.W., Judge, J.O., King, A.C., Macera, C.A., Castaneda-Sceppa, C. (2007). Physical activity and public health in older adults: recommendation from the American College of Sports Medicine and the American Heart Association. Circulation, 116(9), 1094-105.

Paffenbarger, R.S., Jr., Kampert, J.B., Lee, I.M. (1997). Physical activity and health of college men: longitudinal observations. International Journal of Sports Medicine, 18(S3), S200-3.

Paffenbarger, R. (2000). Physical exercise to reduce cardiovascular disease risk. The Proceedings of the Nutrition Society, 59(3), 421-2.

Pescatello, L.S., Franklin, B.A., Fagard, R., Farquhar, W.B., Kelley, G. A., Ray, C.A. (2004). American College of Sports Medicine position stand. Exercise and hypertension. Medicine and Science in Sports and Exercise, 36(3), 533-53.

Peters, P.G., Alessio, H.M., Hagerman, A.E. (2006). Short-term isometric exercises reduces systolic blood pressure in hypertensive adults: possible role of reactive oxygen species. International Journal of Cardiology, 110(2), 199-205.

Petersen, A.M.W., Pedersen, B.K. (2005). The anti-inflammatory effect of exercise. Journal of applied physiology, 98(4), 1154-62.

Pinto, R.R., Polito, M.D. (2015). Haemodynamic responses during resistance exercise with blood flow restriction in hypertensive subjects. Clinical Physiology and Functional Imaging. 1-7.

Prestes, J., Shiguemoto, G., Botero, J.P., Frollini, A., Dias, R., Leite, R., Pereira, G., Magosso, R., Baldissera, V., Cavaglieri, C., Perez, S. (2009). Effects of resistance training on resistin, leptin, cytokines, and muscle force in elderly post-menopausal women. Journal of sports sciences, 7(14), 1607-15.

Reeves, G.V., Kraemer, R.R., Hollander, D.B., Clavier, J., Thomas, C., Francois, M., Castracane, V.D. (2006). Comparison of hormone responses following light resistance exercise with partial vascular occlusion and moderately difficult resistance exercise without occlusion. Journal of Applied Physiology, 101(6), 1616-22.

Renzi, C.P., Tanaka, H., Sugawara, J. (2010). Effects of Leg Blood Flow Restriction during Walking on Cardiovascular Function. Medicine and Science in Sports end Exercise, 42(4), 726-32.

Rexrode, K.M., Pradhan, A., Mansos, J.E., Buring, J.E., Ridker, P.M. (2003). Relationship of total and abdominal adiposity with CRP and IL-6 in women. Annals of Epidemiology, 13(10), 674-82.

Rolim, L.M.C., Amaral, S. L., Monteiro, H.L. (2007). Hipertensão e exercício: custos do tratamento ambulatorial, antes e após a adoção da prática regular e orientada de condicionamento físico. Hipertensão. 10(2), 54-61.

Sakamaki, M., Fujita, S., Sato, Y., Bemben, M.G., Abe, T. (2008). Blood pressure response to slow walking combined with KAATSU in the eldery. International Journal of Kaatsu Training Research, 4(1), 17-20.

Sanhueza, S., Mascayano, M. (2006). Impacto del ejercicio en el adulto mayor hipertenso. Revista Hospital Clinico Universidad de Chile, 17(2), 111-128.

Satoh, I. (2011). Kaatsu Training: application to metabolic syndrome. International Journal of Kaatsu Training Research, 7(1), 7-12.

Sociedade Brasileira de Cardiologia/ Sociedade Brasileira de Hipertensão / Sociedade Brasileira de Nefrologia (2010). VI Diretrizes Brasileiras de Hipertensão. Arquivos Brasileiros de Cardiologia, 95(1/1), 1-51.

Spranger M.D., Krishnan A.C., Levy P.D., O’Leary D.S., Smith S.A. Blood flow restriction training and the exercise pressor reflex: a call for concern. American Journal of Physiology. Heart and Circulatory Physiology. 309(9), H1440-52.

Steensberg, A., Fischer, C.P., Keller, C., Moller, K., Pederson, B.K. (2003). IL-6 enhances plasma IL-1 ra, IL-10 and cortisol in humans. American Journal of Physiology, Endocrinology and Metabolism, 285, 433-437.

Takano H, Morita T, Iida H, Kato H, Uno K, Hirose K, Matsumoto, A., Takenaka, K., Hirata, Y., Furuichi, T., Eto, F., Nagai, R., Sato, Y., Nakajima, T. (2005). Effects of low-intensity "KAATSU" resistance exercise on hemodynamic and growth hormone responses. International Journal of Kaatsu Training Research, 1(1), 13-18.

Takarada, Y., Sato, Y., Ishii, N. (2002). Effects of resistance exercise combined with vascular occlusion on muscle function in athletes. European Journal of Applied Physiology, 86(1), 308-14.

Taylor-Tolbert, N.S., Dengel, D.R., Brown, M.D., McCole, S.D., Pratley, R.E., Ferrell, R.E., Hagberg, J. M. (2000). Ambulatory blood pressure after acute exercise in older men with essential hypertension. American Journal of Hypertension, 13(1), 44-51.

Terra, D.F., Mota, M.R., Rabelo, H.T., Bezerra, L.M.A., Lima, R.M., Ribeiro, A.G., Vinhal P.H., Dias R.M., Silva, F.M. (2008). Reduction of arterial pressure and double product at rest after resistance exercise training in elderly hypertensive women. Arquivos Brasileiros de Cardiologia, 91(5), 274-9.

Umbel, J.D., Hoffman, R.L., Dearth, D.J., Chleboun, G.S., Manini, T.M., Clark, B.C. (2009). Delayed-onset muscle soreness induced by low-load blood flow-restricted exercise. European Journal of Applied Physiology, 107, 687-95.

Vitor, R.S., Sakai, F.K., Consoni. P.R.C. (2009). Indicação e adesão de medidas não farmacológicas no tratamento da hipertensão arterial. Revista da AMRIGS, 53(2), 117-121.

Wernbom, M., Augustsson, J., Thomee. R. (2006). Effects of vascular occlusion on muscular endurance in dynamic knee extension exercise at different submaximal loads. Journal of Strength and Conditioning Research, 20(2), 372-7.

Westhoff, T.H., Franke, N., Schimidt, S., Vallbracht-Israng, K., Zidek, W., Dimeo, F., Van Der Giet, M. (2007). Beta-blockers do not impair the cardiovascular benefits of endurance training in hypertensives. Journal of Human Hypertension, 21(6), 486-493.

World Health Organization. (2013). World Health Statistics. Retrieved from: http://www.who.int/gho/publications/worldhealthstatistics/ ENWHS2012Brochure.p 


\section{Authors' note}

Marcos Antônio Cezar is affiliated with the Unoesc University - Department of Physical Education.

Clodoaldo Antônio De Sá is affiliated with the Unochapecó University. Biochemestry and Exercise Physiology Laboratory, Health Sciences Postraduate Program and VITA Research Group.

Vanessa da Silva Corralo is affiliated with the Unochapecó University. Biochemistry and Exercise Physiology Laboratory, Health Sciences Postgraduate Program and VITA Research Group.

Marzo Edir da Silva Grigoletto is affiliated with the Federal University of Sergipe. Department of Physical Education - Health Sciences Center. Unochapecó University, VITA Research Group.

Sedinei Lopes Copatti is affiliated with the Unochapecó University. VITA Research Group and Health Sciences Postgraduate Program.

Guilherme Augusto Gonzaga dos Santos is affiliated with the Unochapecó University. VITA Research Group.

\section{Corresponding author}

Clodoaldo Antônio De Sá

Avenida Senador Atílio Fontana, 591-E, Bairro EFAPI, Caixa Postal: 1141, Chapecó, SC, Brazil.

Email: clodoaldodesa@gmail.com

Manuscript received on July 18, 2015

Manuscript accepted on February 02, 2016

(c) (7)

Motriz. The Journal of Physical Education. UNESP. Rio Claro, SP, Brazil - eISSN: 1980-6574 - under a license Creative Commons - Version 3.0 